\title{
Gênero e as Relações Internacionais: o Uso da Violência Sexual como Arma de Guerra
}

\author{
Flávia Werner Scholz ${ }^{1}$
}

\begin{abstract}
Resumo
O presente artigo aborda a prática da violência sexual quando utilizada como arma de guerra e a relação oriunda entre as questões de gênero e a perpetuação dessa em áreas de conflito. A pesquisa utiliza-se de uma perspectiva feminista, mediante o apontamento de fatores que buscam explanar sobre o problema. O estudo propõe uma articulação entre o estudo de gênero nas RI, a desigualdade de gênero e a prática da violência sexual como arma de guerra. A partir das elucidações apresentadas, confirma-se a hipótese do trabalho de que ignorar as peculiaridades e violências específicas pelas quais as mulheres são historicamente e frequentemente submetidas, corrobora para que essas continuem sendo perpetuadas em áreas de conflito.Com contribuições de teóricos como J. Ann Tickner, Kimberlé Crenshaw, Fred Halliday, Joan Scott,Tatiana Moura entre outros,apresentam-se entendimentos acerca das questões de gênero na ciência e sua relação com as Relações Internacionais contemporâneas. Discorre-se sobre violência de gênero e sua perpetuação em conflitos compreendendo que o conceito de interseccionalidade é fundamental para análise de tal violência. Observa-se como é imprescindível que o tema seja discutido no âmbito das Relações Internacionais, uma vez que a solução para esse problema se liga intrinsecamente à garantia dos Direitos Humanos, à promoção da equidade de gênero e do re-estabelecimento da paz.
\end{abstract}

Palavras-chave: Gênero;Violência Sexual; Relações Internacionais.

\section{Abstract}

The following work aims to understand the sexual violence when used as war weapon and the relationship between gender problems and the perpetuation of it in areas of conflict. The research uses a feminist perspective, by pointing out factors that seek to explain the problem of this study. The study proposes a link between the study of gender in International Relations, gender inequality and the practice of sexual violence as a weapon of war. From the elucidations presented, the hypothesis of the work is confirmed that ignoring the peculiarities and specific violence by which women are historically and frequently submitted, corroborates that they continue being perpetuated in areas of conflict. With contributions from the theorists such as J. Ann Tickner,Kimberlé Crenshaw, Fred Halliday, Joan Scott, Tatiana Moura and others, discusses understandings of gender issues in science and their relation to contemporary international relations. The specific objectives include the need to focus the understanding

${ }^{1}$ Centro Universitário Uninter. 
ofgender issues in science and its relation to contemporary international relations. The discussion on gender violence and its perpetuation in conflicts is elaborated, understanding that the concept of intersectionality is fundamental for the analysis of such violence.It addresses gender violence and its perpetuation in conflicts, understanding that the concept of intersectionality is fundamental for analyzing such violence. It is necessary to discuss the issue in the context of International Relations, since the solution to this problem is intrinsically linked to the guarantee of Human Rights, the promotion of gender equity and the re-establishment of peace.

Keywords: Gender; Sexual Violence; International Relations.

\section{Introdução}

No presente artigo são tratadas questões relacionadas à violência sexual, esta pode ser evidenciada de diferentes maneiras: por meio de abusos, exploração sexual, assédio sexual, estupros, entre outras (UN, 1994, p.3) ${ }^{2}$. Embora o espectro seja extenso, o objeto estudo é a prática da violência sexual quando utilizada como arma de guerra. Observa-se que tal prática não deve ser considerada como sendo mero produto da guerra (HAYDEN, 2000), mas sim como uma violência que se relaciona aos diversos aspectos ligados à opressão da mulher. Compreende-se que em situações de conflito, tais abusos ganham novos entornos e especificidades, se manifestando com ainda mais força.

A pesquisa utiliza de perspectivas feministas que auxiliam para o entendimento de um problema que se configura como um dos mais preocupantes desafios internacionais. No que tange à metodologia, essa consistiu em uma revisão de literatura, seguida de uma pesquisa bibliográfica baseada em estudos que discutem sobre o tema. Discute-se o processo de inserção das questões de gênero nas Relações Internacionais e a relação oriunda entre a resistência em agregar tais questões e a ineficiência em solucionar problemas das quais as mulheres se configuram como principais vítimas.

Entende-se que, ao passo que por muito tempo as questões de gênero foram invisibilizadas ou ignoradas, houve um determinado momento em que já não era mais possível ignorar as atrocidades pelas quais as mulheres estavam sendo submetidas. Episódios como o conflito da Bósnia - Herzegovina ${ }^{3}$, entre outros, demonstram a magnitude de

\footnotetext{
${ }^{2}$ Declaração da Eliminação da Violência Contra Mulher. Disponível em: https://documents-ddsny.un.org/doc/UNDOC/GEN/N94/095/05/PDF/N9409505.pdf?OpenElement Acesso em 22. Nov. 2016.

${ }^{3}$ A guerra na Bósnia-Herzegóvina (1992-1995) foi um conflito armado que ocorreu entre os anos de 1992 e 1995. Caracterizado pelaviolência hedionda e limpeza étnica, via expulsão, agressão, assassinatos, tortura, estupros, massacres e medo, que levou à reorganização populacional e à divisão do território (PERES, 2011, p.10). Via-se a presença de campos de estupro, geralmente escolas, armazéns, ginásios, hotéis, as mulheres principalmente as bosniaquinhas (muçulmanas bósnias) - onde as mulheres eram forçadas a ter relações sexuais
} 
problemas que começaram a ser denunciados somente pela emergência de movimentos contestadores. Assim, pode-se notar que a mulher, apesar de participar ativamente dos processos, foi colocada em segundo plano pela maior parte das teorias de Relações Internacionais (RI), como um campo pertencente a outro nível de análise (MONTE, 2013).

Demonstra-se a importância dos estudos de gênero para o agendamento de discussões que não eram evidenciadas como é o caso da violência sexual quando utilizada como arma de guerra. Aborda-se a questão da interseccionalidade, uma vez que os principais exemplos de opressão intersecccional são geralmente os mais trágicos: a violência contra as mulheres baseada na raça ou na etnia (CRENSHAW, 2002, p.178), revelando um somatório de opressões que deve ser considerado. Segundo Kimberlé Crenshaw, essa violência pode ser concebida como uma subordinação interseccional intencional, já que, por exemplo, o racismo e o sexismo podem se manifestar conjuntamente em tais violações, refletindo um enquadramento racial ou étnico das mulheres, a fim de concretizar uma violação explícita de gênero (CRENSHAW, 2002, p.178).

Como objetivo principal delineia-se a discussão de que ignorar as peculiaridades e violências específicas pelas quais as mulheres são frequentemente submetidas se caracteriza como uma das formas de contribuir para que essas continuem sendo perpetuadas. Como objetivo específico aponta-se a relação das questões de gênero na ciência e o desenvolvimento das Relações Internacionais contemporâneas. Apresenta-se autoras como Ann Tickner, Cynthia Enloe,Kimberlé Crenshaw, Suzan Browmiller entre outras e outros. Discute-se a violência sexual em situações de conflito e aspectos relacionados à desigualdade de gênero que revelam que a violência contra mulher tem sido uma constante ao longo da história e não deve ser estudada sem considerar as devidas especificidades. Enfatiza-se que a guerra e as relações de poder político se configuram como objetos de estudo das Relações Internacionais e são fundamentais para compreender o tema central desse trabalho, visto que não é só o poder político e econômico, mas também o de gênero que regem as relações internacionais.

\section{Teoria feminista das relações internacionais}

No presente artigo investiga-se a contribuição da perspectiva feminista nas Relações Internacionais, de maneira a ampliar o debate e trazer à tona aspectos referentes ao desenvolvimento da área quando há a inclusão das questões de gênero. J. Ann Tickner em seu

com mais de um soldado e várias vezes. (PERES, 2011). Em termos numéricos, calcula-se que cerca de vinte mil mulheres muçulmanas e croatas foram estupradas durante a guerra. (PERES, 2011, p.10). 
livro intitulado 'Gender in international relations: feminist perspective on achieving global security' (1992) discorre sobre as diversas perspectivas feministas contemporâneas que se voltam para os fenômenos e temas das RI. Tickner tece importantes críticas à exclusão das mulheres, principalmente sobre as tradicionais correntes ${ }^{4}$, explorando as transformações nas análises quando as questões de gênero são incorporadas.A autora apresenta que a condução da política externa e militar foi historicamente conduzida por homens $(1992$, p.8) e pontua:

\begin{abstract}
Nós raramente percebemos que pensamos nesses termos, no entanto; na maioria das áreas do conhecimento que temos nos acostumamos a equacionar o que é humano com o que é masculino. Em nenhum lugar isso é mais verdadeiro do que em relações internacionais, uma disciplina que, enquanto a maior parte resistiu à introdução de gênero em seu discurso, baseia os seus pressupostos e explicações quase inteiramente sobre as atividades e experiências de homens. Qualquer tentativa de introduzir uma análise mais explicitamente de gênero no campo precisa portanto, começar com uma discussão sobre a masculinidade. (TICKNER, 1992, p. 8, tradução livre $)^{5}$.
\end{abstract}

Observa-se que a análise dessas atividades foi feita tendo, sobretudo, aspectos referentes a homens e (em decorrência) masculinidades, como elementos principais. Tickner ressalta a estreita relação entre masculinidade e a política, de tal modo que características associadas à "virilidade" tais como tenacidade, poder, independência, tem sido as mais valorizadas na condução da política ao longo da história, principalmente ao que se refere ao campo da política internacional $(1992$, p.8). Tais processos culminaram no desenvolvimento da área de tal modo que a hierarquia entre os gêneros se perpetuou, sendo tudo aquilo que é considerado "masculino" tido como superior. Nota-se que por algum tempo negou-se e, quando não foi mais possível, retardou-se a inserção das mulheres como atores relevantes nas Relações Internacionais. ${ }^{6}$ Assim, as teorias femininas não devem se restringir à mera inserção da experiência das mulheres, mas que, devem ir além, no sentido de desafiar os conceitos que sustentam as disciplinas (1992, p.9). Mediante o exposto, a autora apresenta:

\footnotetext{
${ }^{4}$ Como a corrente realista, liberal e teorias marxistas. Ressalta-se também a existência de diferentes correntes do pensamento feminista e a multiplicidade de temas, enfoques e embates presentes em cada uma.

${ }^{5}$ We seldom realize we think in these terms, however; in most fields of knowledge we havebecome accustomed to equating what is human with what is masculine. Nowhere is this more true than ininternational relations, a discipline that, while it has for the most part resisted the introduction of genderinto its discourse, bases its assumptions and explanations almost entirely on the activities andexperiences of men. Any attempt to introduce a more explicitly gendered analysis into the field musttherefore begin with a discussion of masculinity.(TICKNER, 1992, p.8).

${ }^{6}$ É possível apontar que os estudos feministas convergem quanto à perspectiva metodológica, contrária às bases androcêntricas sobre a qual a disciplina de RI tem sido edificada. Principalmente porque diversas teorias convergem no entendimento de que a invisibilidade das mulheres não poderá ser resolvida simplesmente adicionando as mulheres ao estado, aos processos capitalistas e às teorias (MOURA, 2012, p.28). Assim, é importante observar que a principal proposta se refere ao questionamento em torno do que é validado como "conhecimento", de modo que se introduziu o sentido de processo (no qual a produção intelectual resulta de um movimento dialético entre textos, ideias e experiências empíricas) (MOURA, 2012, p.28).
} 
Basear-se em teorias feministas para analisar e criticar o significado destes e outros conceitos fundamentais da política internacional pode nos ajudar a reformular estes conceitos de maneira que nos permita enxergar novas possibilidades para resolver nossas inseguranças atuais. (TICKNER, 1992, p. 9, tradução livre) ${ }^{7}$.

Desse modo, observa-se a importância das teorias feministas na fomentação de discussões e novos entornos a temas, enunciados e fenômenos relacionados à área. Tais contribuições podem ser amplamente utilizadas nos processos que objetivam a solução de problemas não se restringindo apenas ao nível doméstico, mas também ao internacional. Tickner argumenta:

Sugerindo que o pessoal é político, os estudos feministas chamaram a atenção para distinções entre o público e o privado na política doméstica: examinar as fronteiras artificiais das distinções na política doméstica pode lançar uma nova luz sobre as fronteiras internacionais, tais como aqueles entre a anarquia e ordem, que são tão fundamentais para o quadro conceitual do discurso realista. (TICKNER, 1992, p.9, tradução livre) $)^{8}$.

A autora apresenta a importância das perspectivas que questionam os papéis de gênero nas relações internacionais, sendo essas capazes de oferecer formas mais inclusivas e humanas de se pensar sobre o futuro coletivo, um futuro em que as mulheres e os homens possam compartilhar igualmente na construção de um mundo mais justo e seguro (1992, p.18). Dessa maneira, Carolina Moreira apresenta:

A introdução das questões de gênero em RI constituiu uma inovadora transformação, uma vez que oferece, finalmente, visibilidade ao caráter sexuado das políticas a um nível global demonstrando, ao mesmo tempo, como este afeta as vidas das pessoas, num caráter mais individual e as vidas das mulheres, de uma forma particular. (MOREIRA, 2012, p.17).

Assim, parte-se para a confluência e aprofundamento das questões de gênero na área utilizando de uma gama de autores(as) que contemplam aspectos circundantes.

\section{Gênero e as relações internacionais}

Objetivando desenvolver o tema, apresenta-se autoras como Cynthia Enloe, Kimberlé Crenshaw, Barbara Smith, autores como Fred Halliday, Messari e Nogueira entre outros.

\footnotetext{
${ }^{7}$ Drawing on feminist theories to examine and critique the meaning ofthese and other concepts fundamental to international politics could help us to reformulate these conceptsin ways that might allow us to see new possibilities for solving our current insecurities.'(TICKNER, 1992, p.9).

${ }^{8}$ Suggesting that the personal is political, feminist scholars have brought to our attention distinctions between public and private in the domestic polity: examining these artificial boundary distinctions in the domestic polity could shed new light on international boundaries, such as those between anarchy and order, which are so fundamental to the conceptual framework of realist discourse.(TICKNER, 1992, p.9).
} 
Ademais, são abordados alguns pontos de J. Ann Tickner que contribuem com a discussão acerca da inserção das questões de gênero na disciplina.

Ao encontro com o pensamento de diversas teóricas feministas ${ }^{9}$, é possível apontar certa negligência no tratamento dado aos estudos de gênero nas Relações Internacionais decorrente de uma hierarquização de temas, atividades e objetos de estudo tidos como 'masculinos'. Apresenta-se confluência do pensamento feminista às Relações Internacionais e o desenvolvimento desses processos que buscaram romper com essa lógica e desconstruir os enunciados que mantinham as questões de gênero afastadas da área. Tais entendimentos auxiliaram para que o problema da violência sexual utilizada como arma de guerra fosse evidenciado como uma questão digna de atenção e esforços. Assim, sobre a emergência de tais questionamentos, Izabela Xavier do Monte argumenta:

\begin{abstract}
Nesse sentido, questionar-se sobre o lugar que as mulheres (não) ocupam no cenário internacional é apenas um primeiro passo para se pensar, a partir da crescente literatura feminista do campo, relações de desigualdade e opressão entre gêneros na política internacional. Mais do que verificar as causas e as consequências da baixa presença de mulheres nos espaços onde as relações internacionais acontecem, leituras feministas de Relações Internacionais extrapolam suas críticas em direção a como representações e papéis de gênero - de maneira simplificada, estereótipos sociais sobre masculinidade e feminilidade - influenciam e se relacionam à condução histórica da política mundial. A partir desses questionamentos, abrem-se discussões sobre o que é considerado objeto de estudo pela disciplina e sobre que forma de ciência é concebida como legítima para estudá-las; em outras palavras, debates e reflexões sobre como a disciplina das Relações Internacionais é construída, e como ela deve se reconstruir. (MONTE, 2014, p.3).
\end{abstract}

Nesse contexto, Cynthia Enloe em seu livro 'Does Khaki Become You? The Militarisation of Women's Lives' (1983) aborda as diferentes maneiras pelas quais as mulheres se relacionam com a política internacional. Evidencia-se a participação das mulheres nas políticas globais, de modo a situá-las nas análises sobre guerra, militarismo e segurança (MOREIRA, 2012, p.16). A autora ainda argumenta:

Convencionalmente tanto a masculinidade quanto a feminilidade foram tratados como algo "natural", e não criado. Hoje, no entanto, há evidências crescentes de que eles são pacotes de expectativas que foram criadas por meio de decisões específicas por pessoas específicas. Também estamos começando a perceber que os conceitos tradicionais de masculinidade e feminilidade têm sido surpreendentemente difíceis de perpetuar: exige-se o exercício diário de poder - poder doméstico, o poder

\footnotetext{
${ }^{9}$ Como reitera Carolina Moreira (2012) há diversas teóricas feministas que acreditam que as mulheres não têm estado ausentes do campo das Relações Internacionais, mas sim invisíveis. Entre elas, estão as autoras já apresentadas Cynthia Enloe e J. Ann Tickner. Observa-se que essa asserção em torno da invisibilidade, dá mote e ponto de partida para toda a investigação feminista em R.I alicerçada na indagação “onde estão as mulheres?". (MOREIRA, 2012, p.16).
} 
nacional e, como veremos, o poder internacional. (ENLOE, 1990, p.3, tradução livre) ${ }^{10}$.

Enloe (1990) elabora uma reflexão acerca de questões que envolvem o cenário internacional, sobretudo da economia política internacional, de modo que essas se revelam como realidades profundamente sexuadas (MOREIRA, 2012, p.16). Chama-se atenção sobre como a intermediação do dia-a-dia do poder global é dependente das construções de gênero, perpetuando estereótipos e a dicotomia entre masculino e feminino. Enloe ressalta dimensões culturais, sociais, e políticas que enfatizam como a desigualdade entre os gêneros pode culminar em uma morosidade da área para absorver temas e discussões pertinentes à segurança das mulheres no contexto internacional.

Nesse sentido, observa-se que "assuntos externos são escritos sobre com um total desrespeito às revelações feministas sobre como o poder depende da obtenção continuada noções sobre masculinidade e feminilidade"' (ENLOE, 1990, p. 4, tradução livre) ${ }^{11}$.Ana Telles de Souza (2014) ressalta que para Enloe (1990) um dos problemas centrais do campo referese à sistemática subestimação das quantidades e variedades de poder que operam na política internacional (SOUZA, 2014, p. 4). Sendo preciso tornar visível e questionar as hierarquias e desigualdades, inclusive as de gênero (ENLOE, 1990). A autora ainda destaca que as noções de masculinidade não são idênticas e ressalta a transmutabilidade dessas ao longo de gerações e limites culturais que trazem diferentes entornos e especificidades a cada uma. Desse modo apresenta:

\begin{abstract}
A rivalidade masculinizada é aquela em que diversas masculinidades são desigualmente classificadas e contestadas: há uma disputa sobre qual a expressão de masculinidade é considerada a mais "moderna", qual é a mais "racional", qual é a "mais difícil", a "mais suave, qual é a " mais fraca". Em tais rivalidades, as mulheres são marginalizadas, a menos (que suportem o ridículo como sendo "pouco feminina") podem convincentemente-se camuflar-se em um estilo masculinizado particular de discurso e ação. Assim, uma avaliação britânica comum de primeira e única mulher primeiro-ministro da Grã-Bretanha: "Margaret Thatcher era o homem mais duro no quarto". (ENLOE, 1990, p. 62, tradução livre) ${ }^{12}$.
\end{abstract}

\footnotetext{
${ }^{10}$ Conventionally both masculinity and femininity have been treated as 'natural', not created. Today, however, there is mounting evidence that they are packages of expectations that have been created through specific decisions by specific people. We are also coming to realize that the traditional concept of masculinity and femininity have been surprisingly hard to perpetuate: it has required the daily exercise of power- domestic power, national power, and, as we will see, international power. (ENLOE, 1990, p.3). Disponível em: http://www.monitor.upeace.org/archive.cfm?id_article=964. Acessi em: 20 nov. 2016.

${ }^{11}$ Foreign affairs are written about with a total disregard for feminist revelations about how power depends on sustaining notions about masculinity and femininity. (ENLOE, 1990, p. 4).

${ }^{12} \mathrm{~A}$ masculinized rivalry is one in which diverse masculinities are unequally ranked and contested: there is a contest over which expression of manliness is deemed most "modern," which most "rational," which the "toughest," which the "softest," which the "weaker". In such rivaries, women are marginalized unless (withstanding ridicule as "unfeminine") they can convincingly cloak themselves in a particular masculinized
} 
Sobre a masculinidade hegemônica que se sobrepôs, ignorando as outras diversas formas de existência e possibilidade de relações (pode-se pensar na transexualidade ou qualquer ordem que fuja ao sistema heteronormativo, por exemplo). Tickner complementa que "a masculinidade hegemônica é sustentada através de sua oposição a várias masculinidades subordinadas e desvalorizadas, como a homossexualidade, e, mais importante, através da sua relação com as diversas feminilidades desvalorizadas" (TICKNER, 1992, p.9,tradução livre $)^{13}$.Dentro desse contexto, é imprescindível pontuar os debates que ocorrem também no campo de estudos feministas. Enfatiza-se que teoria feminista, embora sejam diversas, tragam novas perspectivas e contribuições imensuráveis, também podem se configurar como um espaço onde há a manutenção de desigualdades e opressões. Ressalta-se Bárbara Smith, que tece importantes críticas ao conhecimento feminista que é produzido sem abarcar as diferentes experiências:

O feminismo é teoria política e prática que luta para libertar todas as mulheres: as mulheres de cor, as mulheres da classe trabalhadora, mulheres pobres, as mulheres com deficiência, lésbicas, mulheres idosas - bem como as brancas, economicamente privilegiadas, mulheres brancas heterossexuais. Qualquer coisa a menos que esta visão de liberdade total não é feminismo, mas apenas autoengrandecimento feminino.(SMITH, 1979, p. 48. Tradução livre) $)^{14}$

Evidencia-se, portanto, a necessidade de uma forma de produção do conhecimento que problematize as relações raciais, de classe, etnia, gênero e outras. Vale-se da contribuição de Kimberlé Crenshaw (1979), importante teórica feminista, que argumenta que não se pode permitir que as diferenças entre mulheres marginalizem alguns problemas de direitos humanos das mulheres, nem que lhes sejam negados cuidados e preocupação iguais sob o regime predominante dos direitos humanos (CRENSHAW, 1979, p. 173). Assim:

A lógica da incorporação da perspectiva de gênero, ou seja, focalizar a diferença em nome de uma maior inclusão aplica-se tanto às diferenças entre as mulheres como às

style of speech and action. Thus a common British assessment of Britain's first and only woman prime minister: "Margaret Thatcher was the toughest man in the room." (ENLOE, 2004, p.62).

${ }^{13}$ Hegemonic masculinity is sustained through its opposition to various subordinated and devalued masculinities, such as homosexuality, and, more important, through its relation to various devalued femininities. (TICKNER, 1992, p.9).

${ }^{14}$ The reason racism is a feminist issue is easily explained by the inherent definition of feminism. Feminism is the political theory and practice that struggles to free all women: women of color, working-class women, poor women, disabled women, lesbians, old women — as well as white, economically privileged, heterosexual women. Anything less than this vision of total freedom is not feminism, but merely female selfaggrandizement.(SMITH, 1979, p.48). 
diferenças entre mulheres e homens. Há um reconhecimento crescente de que o tratamento simultâneo das várias diferenças que caracterizam os problemas e dificuldades de diferentes grupos de mulheres pode operar no sentido de obscurecer ou de negar a proteção aos direitos humanos que todas as mulheres deveriam ter. Assim como é verdadeiro o fato de que todas as mulheres estão, de algum modo, sujeitas ao peso da discriminação de gênero, também é verdade que outros fatores relacionados à suas identidades sociais, tais como classe, casta, raça, cor, etnia, religião, origem nacional e orientação sexual são "diferenças que fazem diferença", na forma como vários grupos de mulheres vivenciam a discriminação. (CRENSHAW, 1979, p. 173).

Faz-se imprescindível que as múltiplas diferenças estejam presentes no processo de construção teórico-conceitual feminista (CYPRIANO, DIAS, BARBABELA, 2017). Ressalta-se o conceito de interseccionalidade cunhado por Crenshaw (1989) que enquadra as diversas interações da raça e gênero no contexto da violência contra as mulheres de cor (CRENSHAW, 1989, p.12). A autora articula a interação do racismo e do patriarcado, de maneira que seja possível localizar as mulheres de cor tanto em sistemas de sobreposição de subordinação e à margem do feminismo e do antirracismo(CRENSHAW, 1989, p.12). Segundo a teórica:

\begin{abstract}
Quero sugerir que a interseccionalidade oferece uma maneira de mediar à tensão entre as afirmações de identidade múltipla e a necessidade contínua de política grupal por ele ser uma ideia que aborda as diferenças dentro da diferença, referindose a processos permeados por complexidade e variantes, produtos de contextos específicos que são derivados da interação de determinados fatores sociais, econômicos, políticos, culturais e simbólicos. (CRENSHAW, 1989, p.12).
\end{abstract}

Observa-se que os pontos trazidos pela autora auxiliam para o entendimento acerca do uso da violência sexual como arma de guerra, pois frequentemente a inflição dessa violência se relaciona a aspectos além da questão de gênero, como etnia e raça, por exemplo.

Os trágicos eventos de genocídio em Ruanda e na Bósnia foram desencadeados pelas mutilações e pelo estupro de mulheres por motivações étnicas. Tais abusos, caracterizados pela degradação das mulheres, foram perpetrados tanto como ataques contra a honra do grupo quanto, é claro, como atos contra as próprias mulheres. Conforme afirma a Relatora Especial das Nações Unidas, Radhika Coomaraswamy, as mulheres são alvos especiais desse tipo de abuso por serem frequentemente percebidas como representantes da honra simbólica da cultura e como guardiãs genéticas da comunidade. Embora o ataque à comunidade tenha sido execrado como genocídio étnico, essa indignação não sinaliza preocupações com suas vítimas diretas, muitas das quais estão condenadas ao ostracismo, vistas como mulheres maculadas e irremediavelmente degradadas. Em resumo, nas abordagens subinclusivas da discriminação, a diferença torna invisível um conjunto de problemas; enquanto que, em abordagens superinclusivas, a própria diferença é inclusiva. (CRENSHAW, 1979, p. 176). 
Assim, Crenshaw argumenta sobre a dificuldade de identificar a discriminação interseccional em contextos onde as forças econômicas, culturais e sociais silenciosamente moldam o pano de fundo de forma que as mulheres são colocadas acabam sendo afetadas por outros sistemas de subordinação (CRENSHAW, 1979, p. 176). Suas contribuições apontam para a necessidade de colocar as dimensões raciais e de gênero em primeiro plano (CRENSHAW, 1979, p. 176) para análise de tais problemas.

Seguindo a discussão, Tickner aborda que os primeiros alicerces elencados da sociedade internacional, principalmente ao que se refere ao denominado "primeiro debate", 15 , elementos como guerra, poder, honra e soberania (que eram tidos como base para a compreensão da sociedade internacional) corroboraram para essa marginalização no desenvolvimento dos estudos de gênero dentro das Relações Internacionais. Sendo por meio do reforço de estereótipos que as hierarquias de gênero são reproduzidas. Sobre isso, Izadora Xavier do Monte argumenta:

\begin{abstract}
A construção política dos gêneros implica uma valorização superior do masculino e das atividades masculinas e resulta em uma organização da atividade social e política hierarquizada, fazendo com que identidades e atividades que são concebidas como próprias dos homens, ou de características masculinas, tenham maior prestígio, diante de identidades e atividades associadas às mulheres ou a características tidas como femininas. (MONTE, 2013, p.4).
\end{abstract}

As hierarquias estabelecidas culminam na perpetuação das desigualdades entre os gêneros e com o agravamento de violências, uma vez que não se pode abordar a experiência das mulheres de maneira homogeneizante. Segundo Crenshaw, ao mesmo tempo que é aceito que as mulheres nem sempre vivenciam o sexismo da mesma forma [...] o projeto de entender as circunstâncias concretas nas quais o racismo e o sexismo convergem apenas começa a se desenvolver em nível global (CRENSHAW, 2002, p.177). De acordo com a autora:

Como mostram as topologias, o problema interseccional não está simplesmente no fato de não abordar um único tipo de discriminação de forma completa, mas no fato de que uma gama de violações de direitos humanos fica obscurecida quando não se consideram as vulnerabilidades interseccionais de mulheres marginalizadas e, ocasionalmente, também de homens marginalizados (CRENSHAW, 2002, p.177).

Ademais, pontuam-se as contribuições de Messari e Nogueira (2005) que abordam aspectos relacionados à formação da disciplina de Relações Internacionais. Argumenta-se que

\footnotetext{
${ }^{15} \mathrm{O}$ primeiro debate se refere aos "idealistas" (ou institucionalistas) e realistas, no pós-Primeira Guerra. Disponível em: <http://www.scielo.br/scielo.php?script=sci_arttext\&pid=S0104-026X2013000100004>Acesso em 3 nov. 2016
} 
os estudos da área eram centrados majoritariamente em questões relacionadas à alta e a baixa política e sobre a distinção de poder de outras questões, de modo que, por algum tempo, não houve espaço para o feminismo adentrar nos debates estabelecidos. Os autores apontam que “'tal estudo dizia-se neutro e objetivo e, portanto, não havia lugar para questões de identidade em geral e questões de gênero em particular' (MESSARI e NOGUEIRA, 2005, p. 231). Observa-se que tais entendimentos davam margem a um pensamento homogeneizante das Relações Internacionais.

Segundo esse argumento, quando se trata da segurança, se trata da segurança de todos, independentemente de serem homens ou mulheres, crianças ou velhos. A questão é que quem, na academia e na política, tratava dessas questões de segurança eram homens e quem defendia a sobrevivência de todos eram homens. (MESSARI e NOGUEIRA, 2005, p. 231).

De acordo com Fred Halliday,no livro 'Repensando as Relações Internacionais' (2010) o silêncio sobre os avanços feministas na área durou até o fim da década de 1980. Sobre tal cenário, o autor discorre:

Nos últimos 25 anos, as questões de gênero e particularmente aqueles referentes ao lugar e ao papel das mulheres têm adquirido uma importância muito maior dentro das ciências sociais como um todo. Em resposta à ascensão dos movimentos de mulheres em algumas sociedades ocidentais e à produção de um corpo crescente de literatura analítica com relação à posição da mulher, tem havido um desenvolvimento significativo na agenda e nos conceitos estudados em diversas disciplinas acadêmicas. Se isto tem sido especialmente percebido na história e na sociologia, também tem sido evidente na ciência política, na economia e na antropologia e vem adquirindo maior importância na literatura de humanidades mais ideologicamente constituída. Até o final dos anos 1980, existia, entretanto, uma exceção marcante nesta crescente conscientização das questões de gênero: as relações internacionais. (HALLIDAY, 2010, p.161).

Sendo somente no chamado "terceiro debate", ${ }^{16}$ das Relações Internacionais que a abordagem feminista começou a ganhar mais espaço nos embates acadêmicos da área.

Inicialmente, para construir essa trajetória, é preciso esclarecer quais são os termos do terceiro debate em RI, e como um dos seus polos, o pós-positivismo, representa uma ruptura com as formas anteriores de construção de conhecimento na área. De fato, esta é a principal característica do pós-positivismo: a crítica aos esforços teóricos anteriores em RI, desinteressados em incluir em suas análises as variáveis relativas à dimensão social dos fenômenos internacionais (MONTE, 2013, p.3).

Com relação ao Terceiro Debate interparadigmático, esse se desenvolve a partir do embate entre positivistas e pós-positivistas. Messari e Nogueira apresentam que é possível

\footnotetext{
${ }^{16}$ Os movimentos feministas se caracterizavam no seu início especialmente pela luta "contra as guerras e a luta pela igualdade das mulheres". (OLIVEIRA, 2011, p. 51).
} 
pensar o Terceiro Debate como uma sequência de movimentos de questionamento e crítica às teorias estabelecidas na área tendo como intuito a abertura do campo para novas perspectivas. (NOGUEIRA; MESSARI, 2005, p. 17). Sobre as contribuições da perspectiva feminista às Relações Internacionais, os autores apontam:

\begin{abstract}
A contribuição feminista era pouco reconhecida nas Relações Internacionais até a década passada. O impacto dos estudos feministas na disciplina de Relações Internacionais foi muito tardio e ocorreu muito mais tarde que em todas as demais ciências humanas. Contudo, com o estupro de mulheres se tornando uma arma para a limpeza étnica em algumas das guerras de caráter étnico da década de 1990, a disciplina de Relações Internacionais não teve mais como não lidar com a relevância da categoria de gênero na política internacional. Ou seja, uma vez que as mulheres se tornaram alvo de limpeza étnica não por serem de um grupo étnico ou tribal diferente, mas sim por serem o que são, isto é, mulheres, a disciplina teve de descer — quase literalmente - de seu pedestal e precisou lidar com questões de gênero. (NOGUEIRA; MESSARI, 2005, p. 231).
\end{abstract}

Nesse sentido, Tatiana Moura em seu livro 'Atenas e Esparta: Mulheres, Paz e Conflitos Armados' (2005) denuncia as camuflagens, os silêncios e os estereótipos que asseguram a perpetuação de um sistema assente em relações de poder desiguais (RIBEIRO, 2005, p.2). Moura (2003, p.17) discorre sobre a amplitude das propostas feministas:

[...] perante o reconhecimento da existência de novos riscos e ameaças, e a perpetuação de um sistema construído à custa do silenciamento de experiências e da construção estereotipada e antagônica de masculinidade e feminilidade, as propostas feministas das RI pretendem alargar ou redefinir o que é político, do nível micro ao global, da esfera pessoal à internacional, denunciando os impactos que as estruturas macro têm em grupos locais e em indivíduos. (apud MOREIRA, 2012, p.38).

Assim, a impassibilidade daqueles que ocupam posições de poder e o agendamento de temas relevantes aos Estados (que ignoram as diversas manifestações da violência de gênero $)^{17}$ pode ser considerado um agravante no sentido de corroborar com a não coibição das diversas formas de violência. Isso porque parte-se para o entendimento de que os Estados e nações são como configurações e construções históricas que regulam as atividades sexuais na manutenção e garantia da reprodução biológica e social (JESUS, 2014). Diego de Jesus referente à (in)visibilidade de determinados corpos em estratégias de segurança demonstra que isso pode ser uma forma de violência discursiva com a função de reforçar certas

\footnotetext{
${ }^{17}$ Apresentam-se algumas reflexões acerca da palavra gênero. Segundo Cecília Santos e Wânia Izumino (2005) apesar das diversas áreas temáticas e correntes teóricas, existe um consenso de que a categoria gênero abre caminho para um novo paradigma no estudo das questões relativas às mulheres. Assim, gênero pode ser definido como uma relação socialmente construída entre homens e mulheres, de modo que essa serve como categoria de análise para se investigar a construção social do feminino e do masculino (...)". (SANTOS; IZUMINO; 2005, p.11).
} 
hierarquias de gênero, sexualidade e sexo (JESUS, 2014).Dessa maneira, Joan $\operatorname{Scott}^{18} \mathrm{em}$ seu artigo "Gênero: uma categoria útil de análise histórica" (1989) discorre sobre temas relacionados a gênero e poder. A autora questiona os chamados usos descritivos do gênero, isto é, quando há o emprego do termo 'gênero' sem que esse contemple possíveis alterações das perspectivas teóricas. Scott aponta para o desenvolvimento de trabalhos que discorriam sobre "coisas relativas às mulheres", mas que ocorriam sem o devido questionamento das relações estabelecidas entre homens e mulheres. Assim, temas relacionados à diplomacia, à guerra, à alta política, por muito tempo foram estudados (e praticados) ignorando ou excluindo a presença das mulheres.

Em outros termos, esse uso do gênero só se refere aos domínios - tanto estruturais quanto ideológicos - que implicam em relações entre os sexos. Porque na aparência a guerra, a diplomacia e a alta política não têm explicitamente a ver com essas relações. O gênero parece não se aplicar a esses objetivos e, portanto, continua irrelevante para a reflexão dos (as) historiadores (as) que trabalham sobre o político e o poder. Isso tem como resultado a adesão a certa visão funcionalista baseada, em última análise, sobre a biologia e a perpetuação da ideia das esferas separadas na escritura da história (a sexualidade ou a política, a família ou a nação, as mulheres ou os homens). (SCOTT, 1989 p. 7-8).

Scott apresenta que há uma relação inerente entre poder e saber, sendo o gênero intrinsecamente ligado às relações de poder (1989, p.21). Assim, o gênero pode ser considerado uma forma primeira de significar as relações de poder (1989, p.22). Sobre a questão da guerra, mais especificamente, Scott pontua:

\begin{abstract}
A legitimação da guerra - sacrificar vidas de jovens para proteger o Estado - tomou formas diversificadas, desde o apelo explícito à virilidade (a necessidade de defender as mulheres e crianças que de outro modo estariam vulneráveis), até a crença no dever que teriam os filhos de servir a seus dirigentes ou ao rei (seu pai), e até as associações entre masculinidade e poderio nacional. (SCOTT, 1989, p.18-19).
\end{abstract}

A partir dessas contribuições percebe-seque a inflição da violência sexual deve ser pensada lado a lado às questões de poder, sobretudo porque em situações de conflitos há uma disputa constante (e pelos mais diversos atores) sobre o mesmo. E, muitas vezes, o espaço para essa disputa ocorre no corpo das mulheres. Do extenso espectro de violência e exploração em conflitos armados pelas quais as mulheres foram (e são) sujeitas, observa-se

\footnotetext{
${ }^{18}$ Scott propõe o uso da categoria Gênero para a análise histórica - e, por decorrência, para as Ciências Sociais que pretende compreender e explicar significativamente o caráter relacional, transversal e variável dessa categoria analítica. Assim, gênero se constitui como uma categoria de análise histórica, cultural e política, e expressa relações de poder, o que possibilita utilizá-la em termos de diferentes sistemas de gênero e na relação desses com outras categorias, como raça, classe ou etnia, e, também, levar em conta a possibilidade da mudança. (SCAVONE, 2008. p.180).
} 
um processo no qual teóricas feministas sentiram-se instigadas e desdobraram-se em torno do tema.Permeando assim no questionamento das principais teorias políticas que tiveram seus fundamentos estatocêntricos do sistema internacional desafiados. (MOREIRA, 2012, p.3). Resgatando Crenshaw, vale-se de seus apontamentos para compreensão da violência sexual quando utilizada como arma de guerra e sua relação com os avanços dos estudos de gênero.

\begin{abstract}
Essa violência pode ser concebida como uma subordinação interseccional intencional, já que o racismo e o sexismo manifestados em tais violências refletem um enquadramento racial ou étnico das mulheres, a fim de concretizar uma violência explicita de gênero. Tragédias recentes na Bósnia, em Ruanda, no Burundi e em Kosovo ilustram tristemente o fato de que as longas histórias de violência étnica contra as mulheres não estãorelegadas a um passado distante. Enquanto esses são exemplos mais recentes e conhecidos de violência interseccional, essa vulnerabilidade específicanão assumiu papel importante apenas no conflito armado, mas também outros contextos (CRENSHAW, 1979, p.168).
\end{abstract}

Crenshaw ainda apresenta o estupro quando motivado por questões raciais e por vezes precedidos de outras formas de opressão interseccional, como por exemplo, a disseminação de propaganda racista ou sexista explicitamente direcionada às mulheres em um esforço para racionalizar a agressão sexual contra elas (CRENSHAW, 1979, p.168). A propaganda contra as mulheres pobres e racializadas pode não apenas torná-las alvo da violência sexual, mas também pode contribuir para a tendência já demonstrada, de duvidar da honestidade das que procuram pela proteção das autoridades, como é o caso das mulheres Dalit na índia. (CRENSHAW, 1979, p.168). Os pontos trazidos pela autora são fundamentais para melhor entendimento acerca da complexidade do problema em torno do uso da violência sexual em contextos conflituosos.

Assim, revela-se a tamanha importância do agendamento de tais temas e da reformulação da disciplina contemplando as questões de gênero. Parte-se então para a discussão específica sobre a violência sexual quanto utilizada como arma de guerra.

\title{
Violência sexual como arma de guerra
}

A violência contra a mulher se configura como sendo um problema que perpassa as diversas sociedades e se constitui como uma grave violação dos direitos humanos. Observa-se que a mulher ocupa uma posição inferior dentro da hierarquia e lógica das sociedades patriarcais, tendo o seu desenvolvimento pleno impedido por aspectos sociais, culturais e históricos. Na Declaração sobre a Eliminação da Violência contra a mulher, adotada pela Assembleia Geral das Nações Unidas no ano de 1993 discorre-se sobre tais processos: 
[...] Reconhecendo que a violência contra as mulheres constitui uma manifestação de relações de poder historicamente desiguais entre homens e mulheres, que conduziram ao domínio e à discriminação das mulheres por parte dos homens e impediram o progresso pleno das mulheres, e que a violência contra as mulheres constitui um dos mecanismos sociais fundamentais através dos quais as mulheres são forçadas a assumir uma posição de subordinação em relação aos homens [...] (UN, 1993, p. 2, tradução livre) $)^{19}$.

\section{Nessa mesma declaração define-se a violência contra mulher como sendo:}

Qualquer ato de violência baseado no gênero do qual resulte, ou possa resultar, dano ou sofrimento físico, sexual ou psicológico para as mulheres, incluindo as ameaças de tais atos, a coação ou a privação arbitrária de liberdade, que ocorra, quer na vida pública, quer na vida privada. (UN, 1993, p.3, tradução livre) ${ }^{20}$.

Desse modo, aponta-se que a violência sexual faz parte do largo espectro de violências cometidas contra as mulheres, sendo um dos resultados mais visíveis da desigualdade entre os gêneros. Nesse sentido, Ãrino (2010) argumenta:

Para entender o uso da violência sexual como arma de guerra é importante considerar o marco social patriarcal que legitima e dá origem a esta violência. A violência sexual contra as mulheres é uma realidade em qualquer contexto social [...] O controle do corpo feminino tem sido uma constante no patriarcado com muitas diferentes manifestações. Sendo a mais evidente, o controle sua sexualidade e consideração corpo das mulheres como propriedade do sexo masculino.(ARIÑO, 2016, p.7, tradução livre) $)^{21}$.

Elucida-se sobre a violência sexual, entendendo sua magnitude, mas focando em sua prática nas situações de conflito. Compreende-se que tal inflição pode ser considerada um dos diversos e dolorosos produtos da guerra, entretanto, não se deve reduzir a complexidade do tema e estudá-lo sem perpetrar em suas raízes mais profundas. Nota-se que a perniciosidade dos conflitos armados influi na potencialização da opressão feminina, sendo esse um

\footnotetext{
${ }^{19}$ Recognizing that violence against women is a manifestation of historically unequal power relations between men and women, which have led to domination over and discrimination against women by men and to the prevention of the full advancement of women, and that violence against women is one of the crucial social mechanisms by which women are forced into a subordinate position compared with men. Disponível em: https://nacoesunidas.org/acao/mulheres/ Acesso em: 19. Nov. 2016.

${ }^{20}$ Any act of gender-based violence that results in, or is likely to result in, physical, sexual or psychological harm or suffering to women, including threats of such acts, coercion or arbitrary deprivation of liberty, whether occurring in public or in private life.Disponível em: https://nacoesunidas.org/acao/mulheres/ Acesso em: 19. Nov. 2016.

${ }^{21}$ Para entender el uso de la violencia sexual como arma de guerra es importante tener en cuenta el marco social patriarcal que legitima y da lugar a esta violencia. La violencia sexual contra las mujeres es una realidad presente en cualquier contexto social [...] El control del cuerpo femenino ha sido una constante del patriarcado con muy diversas manifestaciones. La más evidente de ellas, el control de su sexualidad y la consideración del cuerpo de las mujeres como una propiedad masculina. (ARIÑO, 2016, p.7).
} 
problema que perpassa os mais diversos âmbitos e que requer, cada vez mais, mudanças estruturais e medidas da comunidade internacional que sejam capazes de promover a seguridade feminina e, consequentemente, possibilite a emergência de paz nos contextos afetados.

Susan Brownmiller, em seu livro ‘Against our Will: men, women and rape' (1974) lança a luz sobre temas que foram invibilizados no cenário internacional por muito tempo. Browmiller apresenta que a violência de gênero, sobretudo as de natureza sexual, pode ser considerada uma constante nos conflitos armados ao longo da história, embora ainda fosse um assunto pouco discutido e até mesmo considerado tabu na época (1975) em que lançou seu trabalho. Brownmiller (1975, p. 389) apresenta que o estupro se relaciona as relações de poder e não a sexo ou satisfação de desejos sexuais e ainda, argumenta sobre a dominação masculina sobre as mulheres que se encontra profundamente internalizada nos valores culturais.

Segundo a autora, o estupro faz parte de um processo de intimidação pelo qual todos os homens mantêm todas as mulheres em um estado de medo permanente. (1975, p.15). Sendo o estupro uma arma usada contra as mulheres pelos homens, tanto em tempos de “paz”' quanto em tempos de "guerra'. Mas em tempo de guerra, a violação é tanto um ataque contra as mulheres como também um ataque contra "o inimigo"'(BROWMILLER, 1975, p.15).No livro 'Sexual violence as a weapon of war? Perceptions, prescriptions, problems in the Congo and beyond' (1998) das autoras Maria Baaz e Maria Stern argumentase que, enquanto a história do estupro na guerra é tão antiga quanto à própria história da guerra, até recentemente, tal prática havia sido largamente ignorada (STERN; BAAZ; 1998 p.1-2).

No entanto, após demasiados séculos de silêncio e negligência, a questão premente da violência sexual em guerra finalmente foi sendo reconhecida na sequência do reconhecimento internacional das violações em massa durante os conflitos armados, tanto em Ruanda (1994) e na Bósnia - Herzegovina (1992-1995). (BAAZ; STERN, 2013, p.1, tradução livre $)^{22}$.

Com a iminência de conflitos que assolaram a vida de milhares de pessoas e fizeram das mulheres vítimas de verdadeiros massacres sexuais, não foi mais possível ignorar a gravidade dos acontecimentos que passaram a ser progressivamente denunciados pelos estudos feministas.

\footnotetext{
${ }^{22}$ However, after far too many centuries of silence and neglect, the pressing issue of sexual violence in war has now finally been recognized in the wake of the international recognition of the mass rapes during the armed conflicts in both Rwanda (1994) and Bosnia-Herzegovina (1992-95). Disponível em: http://www.divaportal.org/smash/get/diva2:617148/FULLTEXT01.pdf. Acesso em: 19 nov. 2016.
} 
A violência sexual como arma de guerra, finalmente começou a receber a atenção que merece, tendo em conta o sofrimento que suas vítimas suportam e de prejudicar a sociedade em certas ocasiões. Na verdade, estamos confiantes de que uma chave fundamental para aprofundar a compreensão e, eventualmente, reparar a violência sexual relacionada com conflitos foi obtida através de seu reconhecimento como um problema de segurança global aguda e grave, como uma "arma de guerra". (BAAZ; STERN, 2013, p.1).

Nota-se que as dificuldades historicamente enfrentadas continuam a se perpetuar e que ainda há muito a ser feito no sentido de ressaltar a responsabilidade e demonstrar que o estupro se relaciona a subjugação, desumanização e exploração das mulheres (que ocorre como uma constante e não apenas em episódios esporádicos ou em contextos belicosos).

Tem que ser entendido que este é um problema de segurança, não apenas homens comportando como homens. Não é uma consequência inevitável da guerra - é algo que é planejado. É algo que pode ser comandado, condenado ou tolerado. Precisamos dizer que podemos pará-lo. Não é inevitável. (Margot Wallström, apud. Crossette 2010) $)^{23}$.

Compreende-se, portanto, a gravidade do problema enquanto ameaça ao bem-estar das mulheres e comunidades afetadas, não sendo, portanto, adequado e pertinente tratar a questão como mera consequência de um conflito armado, mas sim como um problema capaz de ser solucionado. Observa-se a importância da perspectiva feminista ao agendar esse problema na discussão dos atores do cenário internacional e incluir as questões de gênero como fundamentais para o desenvolvimento da disciplina (RI).

\section{Considerações finais}

A partir das elucidações do presente artigo, realizou-se uma exposição acerca das questões de gênero, sua relação com a disciplina de Relações Internacionais e articulação com o problema da violência sexual como arma de guerra. Foram pautados aspectos para o entendimento do quanto os principais pressupostos das RI foram formulados relegando a participação feminina a um segundo plano. Chama-se atenção no sentido de como a ciência que por muito se dizia neutra, corroborou para que a inserção das questões de gênero fosse tardia na área e, consequentemente, muitos dos assuntos que concernem (não só, mas principalmente) as mulheres foram, por algum tempo, conduzidas e estudadas

\footnotetext{
${ }^{23}$ It has to be understood that this is a security problem, not just men behaving like men. It's not an inevitable consequence of war - it's something that is planned. It can either be commanded, condemned or condoned. We need to say that we can stop it. It's not inevitable. (Margot Wallström, cited in Crossette 2010).
} 
majoritariamente por homens. Nota-se a relevância de apresentar tais entendimentos, pois se percebe que tais processos findaram no desenvolvimento da área de tal modo que a hieraquia entre os gêneros se perpetuou, sendo aquilo que é considerado "masculino" tido como superior. Percebe-se, portanto, a imposição de dificuldades (e até mesmo exclusão) da participação feminina em áreas e atividades que eram consideradas predominante masculinas, como a política, diplomacia, entre outras.

Após a exposição de tais processos, discorreu-se sobre a a emergência dos movimentos e estudos que pautavam esse espectro de questões que não eram devidamente contemplados. E ainda, nesse sentido, reiterou-se a importância da absorção de elementos e perspectivas feministas principalmente ao que tange aos temas e fenômenos que começaram a ser pautados ou ganharam novos entornos devido as contribuições feministas para as Relações Internacionais. Foram apresentados entendimentos e aspectos circundantes sobre a prática da violência sexual quando utilizada como arma de guerra. Reiterou-se o entendimento de que tal ação não deve ser considerada como sendo mero produto da guerra, mas sim compreendida abrangendo a multiplicidade de aspectos ligados à opressão pela qual o contingente feminino é submetido (não só na guerra, como também em tempos de paz).

Observa-se que a violência de gênero é uma constante e que em momentos de conflito ganha novos contornos, motivações e especificidades que se somam à expressão da desigualdade que já ocorria anteriormente. Assim, o presente artigo chamou atenção para esse problema que se configura como um dos maiores e mais preocupantes desafios a serem solucionados no plano internacional, objetivando demonstrar a importância das RI no sentido de incorporar uma perspectiva de gênero que agende tais temas.

\section{Referências}

ARIÑO, María V. La violencia sexual como arma de guerra. Quaderns de Construcció de Pau, $\mathrm{n}^{\circ} 15,2010$.

BAAZ, Maria Eriksson. STERN, Maria. Sexual Violence as a weapon of war? Perception, prescriptions, problems in the Congo and beyond. Zed books, 2013.

BARBABELA, Pedro. CYPRIANO, Breno. DIAS, Tayrine. As interseções entre as Relações Internacionais, a teoria política feminista e o feminismo pós/de/colonial na América Latina. $6^{\circ}$ Encontro da Associação Brasileira de Relações Internacionais (ABRI), Pontifícia Universidade Católica, Minas Gerais, 2017.

BROWMILLER, Suzan. Against Our Will: Men, women and rape. New York: Simon and Shuster, 1975. 
CRENSHAW, Kimberlé.Documento para o encontro de especialistas em aspectos da discriminação racial relativos ao gênero. Revista Estudos Feministas. [online]. 2002, vol.10, n.1, jan., 2002. http://www.scielo.br/pdf/ref/v10n1/11636.pdf

MONTE, Izabela Xavier do. Gênero e Relações Internacionais: uma crítica ao discurso tradicional de segurança. Dissertação (Mestrado em Relações Internacionais) - Instituto de Relações Internacionais de Brasília, Brasília, 2010.

ENLOE, Cynthia. Bananas, Beaches and Bases: making feminist sense of international politics. Berkeley and Los Angeles: University of California Press, 1990.

HALLIDAY, Fred. Repensando as Relações Internacionais. Porto Alegre: UFRGS, 1999.

HAYDEN, Robert M. Rape and Rape Avoidance in Ethno-National Conflicts: Sexual Violence in Liminalized States. American Anthropologist, New Series, vol. 102, $\mathrm{n}^{\circ}$ 1, mar. 2000.

JESUS, Diego Santos Vieira. O mundo fora do armário: teoria queer e relações internacionais. Revista Ártemis, Rio de Janeiro, 2014, v7.

MOREIRA, Carolina. O Homem Guerrreiro e os desafios feministas: Perspectivas teóricas feministas em Relações Internacionais e o ativismo anti militarista feminista nos Balcãs. Dissertação de Mestrado em Estudos Europeus apresentada à Faculdade de Letras em Coimbra, 2010.

NOGUEIRA, João Pontes; MESSARI, Nizar. Teoria das Relações Internacionais: correntes e debates. Rio de Janeiro: Elsevier, 2005.

PERES, Andréa Carolina Schvartz. Campos de estupro: as mulheres e a guerra na Bósnia.Cad. Pagu no.37 Campinas July/Dec. 2011.

RIBEIRO, Margarida Calafate. MOURA, Tatiana:Entre Atenas e Esparta: Mulheres, paz e conflitos armados. Revista Crítica de Ciências Sociais, Nº71, 2005.

SANTOS, Cecília M.; IZUMINO, Wânia P. Violência contra as mulheres e violência de gênero: Nota sobre os estudos feministas no Brasil. E.I.A.L. Estudios Interdisciplinarios de América Latina y El Caribe, da Universidade de Tel Aviv, 2005.

SCAVONE, Lucila. Estudos de Gênero: uma sociologia feminista? Estudos Feministas, Florianópolis, vol. 16 n.1, p.173-186, jan/abr. 2008.

SCOTT, Joan W. Gênero: uma categoria útil de análise histórica. TRADUÇÃO: Christine Refine Dabat Maria Betânia Ávila Texto original: Joan Scott - Gender: a useful category of historical analyses. Gender and the politics of history. New York,Columbia University Press. 1989. Educação e Realidade, vol. 16, no 2, Porto Alegre,jul./dez. 1990, p.5.

SMITH, Barbara. Racism and women's studies. Frontier: A Journal of Women's Studies, Lincoln, NE, v. 5, n. 1, p. 48-49, 1979 
TICKNER, Judith Ann. Gender In Internacional Relations:Feminist Perspectivies on Achieving Global Security. New York: Columbia University Press, 1992.

TELLES, Ana Clara de Souza. O pessoal é internacional: como as teorias feministas transformam o estudo das Relações Internacionais.Anais do III Simpósio Gênero e Políticas Públicas, Universidade Estadual de Londrina, 2014. 